\title{
Un camino fluctuante para el análisis del territorio en el devenir del espacio geográfico. El estudio de la costa estuarial bonaerense
}

Fernández Equiza, Ana María

Un camino fluctuante para el análisis del territorio en el devenir del espacio geográfico. El estudio de la costa estuarial bonaerense

Geograficando, vol. 16, núm. 1, 2020

Universidad Nacional de La Plata, Argentina

DOI: https://doi.org/10.24215/2346898Xe070

Atribución no comercial compartir igual (CC BY-NC-SA) 4.0 


\title{
Un camino fluctuante para el análisis del territorio en el devenir del espacio geográfico. El estudio de la costa estuarial bonaerense
}

\author{
Ana Maria Fernández Equiza \\ Centro de Investigaciones Geográficas-Facultad de Ciencias \\ Humanas-Universidad Nacional del Centro de la Provincia \\ de Buenos Aires. Instituto de Geografía, Historia y Ciencias \\ Sociales-Universidad Nacional del Centro de la Provincia \\ de Buenos Aires/CONICET, Argentina
}

DOI: https://doi.org/10.24215/2346898Xe070

Autora: Gabriela Mariana D’Amico - Centro de Estudios Integrales de la Dinámica Exógena (UNLP); Instituto de Investigaciones en Humanidades y Ciencias Sociales (UNLP-CONICET)

Directora: Dra. Claudia B. Carut - Instituto de Investigaciones en Humanidades y Ciencias Sociales (UNLP-CONICET)

Codirector: Dr. Enrique Fucks - Centro de Estudios Integrales de la Dinámica Exógena (UNLP)

Fecha de defensa: 12 de marzo de 2020

La autora analiza el devenir espacial de la costa estuarial bonaerense desde el origen de su poblamiento hasta la actualidad, a partir de un estudio retrospectivo de los cambios en la valoración de disponibilidades territoriales existentes en distintos momentos históricos.

La tesis aborda un tema relevante con un planteo original, fundado en la aproximación al análisis de las interrelaciones entre dinámicas físicas y sociales. Se pregunta: ¿cuáles han sido los mecanismos de conformación de territorios en la costa estuarial del Rio de la Plata al sur de la región metropolitana de Buenos Aires?

Plantea como hipótesis que la costa estuarial bonaerense presenta usos del suelo, marcas y herencias territoriales derivadas de distintas valoraciones del espacio costero, en función de otorgar valor a disponibilidades anfibias existentes en distintos tiempos para la reproducción social y/o económica de ciertos grupos de actores sociales.

La tesis cuenta con cinco capítulos. En el primero se desarrolla la propuesta teórico-metodológica a partir de la consideración de tres ejes: el territorio y el espacio, pasado y presente y tierra-agua. Realiza un análisis multiescalar, relacionando distintos procesos históricos con la construcción social de los territorios.

En el segundo capítulo recupera antecedentes, caracteriza el estuario del Rio de la Plata, realiza una propuesta de delimitación del mismo y fundamenta los recortes territoriales en los que apoya su estudio. Se trata de Isla Paulino, Punta Atalaya, Punta Indio y Punta Piedras, la Desembocadura de los Ríos Samborombón y Salado, y Punta Rasa.

En el tercer capítulo presenta un análisis en profundidad de cada recorte territorial, apoyado en un gran trabajo de campo complementado con el análisis de fuentes históricas y el uso de sistemas de información geográfica. Las particularidades de cada configuración territorial, resultantes tanto de condiciones y procesos físicos como de procesos históricos, son abordadas en detalle. Es destacable que, no obstante la especificidad del tratamiento de cada recorte territorial, la tesis elude la fragmentación y mantiene a la costa del Estuario del Rio de la Plata como totalidad en estudio. En este sentido, el capítulo cuatro profundiza la mirada diacrónicosincrónica. A modo de síntesis, presenta figuras muy logradas. En particular, una línea del tiempo de usos del suelo para cada recorte territorial de la zona costera en estudio desde el siglo V hasta la actualidad, y una figura 
que muestra las tendencias de variación de la línea de costa para los siglos XX y XXI. Ambos elaborados con el apoyo del análisis de imágenes satelitales.

El capítulo 5 se constituye a modo de conclusiones pertinentes y coherentes con el desarrollo de la tesis. La bibliografía es amplia y adecuada.

La tesis aporta al conocimiento de la valoración de las disponibilidades del espacio costero por parte de distintos actores en distintos momentos de la historia. El poblamiento originario testimoniado en los registros arqueológicos conocidos, el emplazamiento de un puerto alternativo al de Buenos Aires, la instalación de saladeros, el emplazamiento de instalaciones militares, la conformación de áreas protegidas, el uso residencial, turístico o para cultivos, usos que cambian y hacen parte del devenir de la construcción social del territorio estudiado. Pero este devenir tiene en el estuario un carácter específico, pues se trata de un espacio anfibio, tierra- agua. La autora presta especial atención a esta fluctuación y esto constituye uno de los aspectos más originales de su trabajo.

El amplio trabajo de campo reflejado en la tesis contribuye a cumplir con la propuesta inicial de leer desde el territorio, escuchando su voz.

La complejidad y extensión del objeto de estudio admite múltiples abordajes. El realizado en la Tesis de Gabriela D'Amico constituye un aporte valioso y original.

\section{BY-NC-SA}

